\title{
Process of Alkylating of Oily Fractions with Catalytic Cracking
}

\section{Gases}

\author{
Huseynova GA*, Muxtarova GS, Rashidova SY and Guliev AI \\ Institute of Petrochemical Processes, National Academy of Sciences of Azerbaijan, \\ Azerbaijan
}

*Corresponding author: Huseynova GA, Institute of Petrochemical Processes, National Academy of Sciences of Azerbaijan, Baku, Azerbaijan, Email: Huseynovaga@mail.ru

\section{Mini Review \\ Volume 3 Issue 6}

Received Date: December 23, 2019

Published Date: December 30, 2019

DOI: $10.23880 /$ ppej-16000212

\section{Abstract}

Possibility of improvement of viscosity-temperature properties of distillate fractions of oils of two levels of viscosity is shown in the process of alkylating with catalytic cracking gases on Zeokar-600 and Omnikat-210 P zeolite catalysts. The viscosity index at alkylating of the oil fraction increases from 79 to 146 and 104 and from 32 to 75 and 53 accordingly on the Zeokar-600 and Omnikat-210P catalysts.

Keywords: Oil distillate fractions; Alkylation; Catalytic cracking gases; Zeokar-600; Omnikat-210 P; Viscosity index

\section{Introduction}

The process of alkylating is used mainly for the receipt of high-antiknock components of petrol's. As an alkylating agent use ethylene, propylene, butene. From individual aromatic hydrocarbons alkylating benzene, toluene, $\mathrm{p}$ xylene, pseudocumene, expose to, and also mixtures of hydrocarbons are products of the oil processing, as for example, low-octane petrol's of the catalytic cracking. From paraffin hydrocarbons most attention is spared to alkylating of i-butane. Application of zeolite catalysts instead of liquid acid in the processes of alkylating in traditional and supercrític terms allows to increase quality of the got alkylates and their selectivity [1-4].

The process of alkylating is also used for the improvement of viscosity-temperature and other properties of mineral oils. Base oils from Azerbaijani an oils differ in unsatisfactory viscosity-temperature properties (by the subzero viscosity index). Oils with the high viscosity index from oils of Azerbaijan it may be to get only by means of alteration of structure of hydrocarbons. Basic direction of improvement of these properties is the use for their receipt of processes changing chemical composition toward formation of hydrocarbons with the higher viscosity index. The satiation of oily fractions isoparaffin hydrocarbons allows to improve their rheological properties, decrease evaporation, increase thermal oxidative stability, and also row of operating indexes. Therefore alkylating is one of methods of increase of isoparaffin hydrocarbons due to converting of paraffins of normal structure into isoparaffin. For the improvement of viscositytemperature properties of distillate oily fractions the process of alkylating is investigational the condensated gases of the catalytic cracking. Last year's gases of the catalytic cracking find all greater application in the processes of oligomerization and alkylating for the receipt of components of fuels and oils.

In our researches gases of catalytic cracking were used as an alkylating agent at alkylating of the distillate oily factions conducted with the purpose of improvement of their viscosity-temperature properties (viscosity index). Depending on the processed raw material on the options of the catalytic cracking quantitative composition of going 


\section{Petroleum \& Petrochemical Engineering Journal}

out hydrocarbon gases is different. From composition of gases, and also the indexes viscosity and viscosity index change from the terms of alkylating of oily factions and applied catalyst. The reaction of alkylating is accompanied by the by-reactions of cracking, oligomerization, aromatization, disproportionation, isomerization, as a result of that there is formation of hydrocarbons of different structure.

\section{Experimental}

Alkylating was conducted on setting of batch-type with a reactor by volume of $250 \mathrm{~mL}$ [5]. The serve of gases was carried out by means of piston liquid pump allowing to regulate the expense of gases depending on their correlation with oily fraction. Alkylating was conducted in the interval of temperatures from 50 to $150^{\circ} \mathrm{C}$, pressure in a reactor $0.4-0.7 \mathrm{MPa}$, pressure of serve of gas $0.25-0.70 \mathrm{MPa}$, by volume correlation oily fraction: gases 1: 1, 1: 2 and 1: 3 . Time of reaction 1-2 hours. Catalysts - Zeokar-600 and Omnikat-210 P.

Alkylating distillate oily fractions exposed to with the viscosity index 79 and 32 . Basic physical and chemical properties are driven to the Table 1 .

\begin{tabular}{|c|c|c|}
\hline \multirow{2}{*}{ Properties } & \multicolumn{2}{|c|}{ Distillate Oils } \\
\cline { 2 - 3 } & Standard 1 & Standard 2 \\
\hline Kinematic viscosity $\left(\mathrm{mm}^{2} / \mathrm{s}\right)$ at: $40^{\circ} \mathrm{C}$ & 9.85 & 27.82 \\
\hline $100^{\circ} \mathrm{C}$ & 2.54 & 4.38 \\
\hline Viscosity index & 79 & 32 \\
\hline Temperature of flash, ${ }^{\circ} \mathrm{C}$ & 152 & 194 \\
\hline Density at $20^{\circ} \mathrm{C}, \mathrm{kg} / \mathrm{m}^{3}$ & 871.2 & 898.4 \\
\hline
\end{tabular}

Table 1: Basic physical and chemical properties of standards of distillate oils.

The values of kinematic viscosity were determined according to GOST 33-2000. The calculation of the viscosity index by kinematic viscosity was carried out in accordance with GOST 25371-97. At alkylating of oily fractions on the catalysts of Zeokar 600 and Omnikat 210 $P$ used gases with different maintenance of olefins. For alkylating of Standard 1 with kinematics viscosity of 9.85 $\mathrm{MM}^{2} / \mathrm{s}$ with at $40^{\circ} \mathrm{C}$ and by the viscosity index 79 on the catalysts of Zeokar 600 and Omnikat $210 \mathrm{P}$ used gases with total maintenance of olefins (vol \% ) 47.3 and 51.4 accordingly. Alkylating of Standard 2 with kinematic viscosity of $27.8 \mathrm{Mm}^{2} / \mathrm{s}$ with and by the viscosity index 32 on Zeokar 600 conducted gases of the catalytic cracking with total maintenance of olefins (vol \%) 57.28, and on
Omnikat 210 P - $47.4[5,6]$. The viscosity-temperature properties and density of alkylates obtained on Zeokar 600 and Omnikat $210 \mathrm{P}$ catalysts under optimal conditions are presented in Table 2.

Those at that there was a most increase of viscosity index at alkylating are certain optimal terms [5-7]. For Standard 1 on the catalysts of Zeokar 600 is a temperature of $100^{\circ} \mathrm{C}$ and Omnikat $210 \mathrm{P}$ is a temperature of $50^{\circ} \mathrm{C}$, correlation of oily fraction: gases 1 : 2. For Standard 2 on the catalysts of Zeokar 600 is a temperature of $50^{\circ} \mathrm{C}$, correlation of oily fraction: gases 1 : 1 and 1: 2 and Omnikat $210 \mathrm{P}$ - temperature of $100^{\circ} \mathrm{C}$, correlation of oily fraction: gases $1: 1$.

\begin{tabular}{|c|c|c|c|c|}
\hline \multirow{2}{*}{ Properties } & \multicolumn{3}{|c|}{ Alkylates } \\
\cline { 2 - 5 } & \multicolumn{2}{|c|}{ Standard 1 } & \multicolumn{2}{c|}{ Standard 2 } \\
\hline & Zeokar-600 & Omnikat-210 P & Zeokar-600 & Omnikat-210 P \\
\hline Kinematic viscosity $\left(\mathrm{mm}^{2} / \mathrm{s}\right)$ at: $40^{\circ} \mathrm{C}$ & 9.24 & 10.13 & 30.9 & 35.7 \\
\hline $100^{\circ} \mathrm{C}$ & 2.75 & 2.71 & 4.95 & 5.13 \\
\hline Viscosity index & 146 & 104 & 75 & 53 \\
\hline Density at $20^{\circ} \mathrm{C}, \mathrm{kg} / \mathrm{m} 3$ & 864.7 & 871.4 & 899.7 & 902 \\
\hline
\end{tabular}

Table 2: Basic physical and chemical properties of alkylates.

\section{Results and Discussion}

As be obvious from a table 2 not only of viscosity index but also kinematics viscosities and densities of alkylates changed. Thus toward the increase of all indexes, except viscosity at $40^{\circ} \mathrm{C}$ and closeness at the first standard got on the catalyst of Seokar 600. Presumably on the catalyst of Seokar 600 at the temperature of $100^{\circ} \mathrm{C}$ little viscid oil 


\section{Petroleum \& Petrochemical Engineering Journal}

had not only tacking of propylene and butane links to aromatic and naphthenes hydrocarbons but also lengthening of chain let of paraffin hydrocarbons or formation of new hydrocarbons in the process of oligomerization. Therefore there was reduction of viscosity at $40^{\circ} \mathrm{C}$. The in this case predominating reaction of process was an oligomerization.

Alkylating of more viscous distillate fraction passed in other direction. As spectral researches showed IR, NMR and UV-methods the structure of molecules, touching a structure and number of lateral chains, and also amount of aromatic hydrocarbons with benzene, naphthalene and by phenanthrene structures, changes in aromatic and naphthenes hydrocarbons of this fraction [6].

Chromatographic determination of gas composition before and after alkylating of oil (Standard 2) showed reduction of concentration of propylene and all olefins with conversion of 95-97 and 78-85\% об Accordingly [8]. Maximal conversion of olefins hydrocarbons made 85.2 and $81.2 \%$ об. at alkylating of this oil on the catalyst of Seokar 600 under constraint $0.6 \mathrm{MPa}$, to the temperature of $50^{\circ} \mathrm{C}$ and correlation oil : gases 1: 2 and 1: 1 accordingly. Thus pressure there was maximal conversion of propylene. At alkylating of the same oil on the catalyst of Omnikat $210 \mathrm{P}$ maximal conversion of olefin hydrocarbons made $72-75 \mathrm{vol} \%$. The viscosity indexes of the alkylates got on these catalysts and corresponding compositions of gases increased as compared to an initial distillate on 38 and 21 point.

Maximal conversion of propylene and olefin hydrocarbons at alkylating of more easy fraction of oil with the higher index of viscosity on the catalyst of Zeokar-600 was 90.0 and 75.0 (vol \%) accordingly. On the catalyst of Omnikat $210 \mathrm{P}$ these indexes considerably below.

As researches showed, to most transformations in the process of alkylating of oils propylene undergoes with different viscosity and viscosity index, in less degree butane 1, trans- and cis-butene-2. In off-gas after alkylating there was a number of again well-educated components of both paraffin and olefin structure in different concentrations. The viscosity index increased in a greater degree just in case of maximal conversion of olefin hydrocarbons entering in the complement of gases of the catalytic cracking. It is necessary also to mark that in investigational terms on the catalyst of Zeokar-600 alkylating does not take place iso-butane butenes entering in the complement of gases of the catalytic cracking. Isobutane is concentrated in off-gas, that can be used in the process of alkylating by his butenes for the receipt of components of high-antiknock petrols.

\section{Conclusions}

Researches of process of alkylating of oily fractions on zeolite catalysts showed, that the increase of viscosity index in a greater degree took place in case of maximal conversion of olefin hydrocarbons entering in the complement of gases of the catalytic cracking and at their maximal maintenance. A catalyst here plays a substantial role also. In this case there is formation of more deputized alkyl naphthenes and alkyl aromatic hydrocarbons with more long alkyl chain, having a higher index of viscosity.

\section{References}

1. Xamzin YA, Shiriyazdanov RR, Davletshin AR, Shadrina AE (2018) Chemistry and technology of fuels and oils. ICST pp: 1-10.

2. Trapeznikova EF, Smolnikova TV, Xafizova CR (2018) Neftegazovie Tekhnol and analitika 10: 50.

3. Solodova NL, Abdullin AI, Emelyanicheva EA (2013) Alkylation of Isoparaffins with Olefins. Khim Tekhnol Chemical Technologies 16(18): 253.

4. Koklin AE, Chan VMX, Kazanski VB, Bogdan VI (2010) Alkylation of isobutane with $\mathrm{C} 4$ olefins under conventional and supercritical conditions. Kinetics and Catalysis 51(3): 410-415.

5. Samedova FI, Huseynova GA, Rashidova S Yu (2016) Mir Nefteprod 1: 18.

6. Huseynova GA, Samedova FI, Rashidova S Yu, Guliev AI, Dzhafarova RA, et al. (2019) A Study of the Products of Alkylation of Turbine Oil Distillate with Catalytic Cracking Gases. Petroleum Chemistry 59(11): 1220-1225.

7. Huseynova GA, Guliev AI, Samedova FI (2016) Neftegaz Tekhnol 9: 26.

8. Huseynova GA, Samedova FI, Babayeva FA (2015) Oil refining and petrochemistry. 12: 30 . 